Send your letters to the Editor,

British Dental Journal,

64 Wimpole Street

London

W1G 8YS

Email bdj@bda.org

Priority will be given to letters less than 500 words long.

Authors must sign the letter, which

may be edited for reasons of space.

\section{NO TO BDA}

Sir, contrary to the view expressed by M. Austin in the 27 March 2010 edition of the BDJ (Membership tardiness; BDJ 2010; 208: 244), dental care professionals (DCPs) have no need to join the British Dental Association - a professional association for dentists. DCPs have their own professional associations which provide information, support and advice on their specific professional requirements; provide CPD tailored to their professional needs; represent their members in discussions with the appropriate bodies; and, in most cases, offer indemnity cover designed specifically for that particular class of DCP (rather than being added on to a dentist's cover as an afterthought).

These DCP associations - contrary to M. Austin's description of them as 'disparate organisations' - work together when necessary on behalf of DCPs, whilst maintaining the individuality and integrity of the various professions which make up the dental team.

Any DCP who is seeking to join an association in order to obtain CPD, indemnity and professional support would be better advised to join their OWN professional association, run by and for members of their own profession, and designed to meet their own specific professional needs.

\section{P. A. Swain, Chief Executive, British}

Association of Dental Nurses

M. Harris, President, British Society for Dental Hygiene and Therapy

C. Allen, Chief Executive, Clinical Dental Technicians Association

S. Adams, Chief Executive, Dental Technicians Association

R. Daniels, Chief Executive, Dental Laboratories Association/British

Association of Clinical Dental Technicians DOI: 10.1038/sj.bdj.2010.405

\section{PRISON DECISIONS}

Sir, I read with much interest your editorial Dentists behind bars (BDJ 2010; 208: 145). I am a Dentist with Special Interest in Prison Dentistry and attended the 3rd annual NAPD(UK) conference you mention.

Having been a prison dentist for some six years, I am pleased that the NAPD(UK) has brought this small proportion of the profession together and raised its profile. Recent recommendations regarding the reform of prison dental services ${ }^{1,2}$ have been positive but the number of clinicians obtaining DwSI in PD remains low. Prisoners have significant dental health needs, have had little previous dental intervention and have a high proportion of mental and physical problems. ${ }^{3,4}$ Ninety percent of prisoners have a mental health problem, a substance misuse problem or both. The demand for emergency care is high as inmates undergoing drug detox discover previously masked dental pain. Substance misusers also have a lowered pain threshold and are commonly dentally anxious. Lifestyle habits contribute to poor dental health as well as the substance misuse. ${ }^{5}$ A high proportion of inmates have language and/or communication difficulties. $^{6}$

It is unfortunate that the time when the role of the prison dentist has formal competencies in the form of DwSI contracts $^{2}$ has coincided with the current financial situation. I have recently had my clinical time reduced by a third and each year 3\% of the prison dental budget is reduced. Under these circumstances, it is very challenging to offer a full service, as emergency patients are always prioritised. Such reductions may prove a false economy as the need for dentistry will not reduce and prisoners taken to outside hospital when the prison dentist is not available are escorted by prison officers, the cost of whose time is recharged to the PCT. It will not need many outside transfers before the cost of the reduced sessions is exceeded.

Each PCT is now responsible for commissioning services within prisons falling within their geographical area. With some PCTs having only one prison in their area, there are many commissioners who are faced with difficult financial decisions over a wide range of healthcare services with which they may not have direct experience or knowledge. There is a risk that all commissioners are required to independently familiarise themselves with prison dental services and current recommendations.

At the conference of NAPD(UK) it was obvious that there were many experienced and skilled prison dentists in attendance. It was, however, generally reported that some commissioners were reluctant to recognise demonstrated competencies by considering a DwSI contract, even when this is cost neutral. It is clear that if this field of dentistry is to provide the best standard of care with skilled clinicians, further attention by understanding commissioners is essential.

\section{R. Edwards Rochdale}

1. Reforming prison dental services in England - a guide to good practice. Department of Health, 2006

2. Guidelines for the appointment of Dentists with Special Interests (DwSIs) in Prison Dentistry. Primary Care Contracting and Faculty of General Dental Practice (UK), 2008

3. Salive M E, Epiee H C, Fell P H, Jones J J, Rico M. Oral health status of a federal prison population. J Public Health Dent 1989; 50: 257-262.

4. Lunn H, Morris J, Jacob A, Grummitt C. The oral health of a group of prison inmates. Dent Update 2003; 30: 135-138. 